\title{
PROFIL KONDISI FISIK ATLET SEPATU RODA DAERAH ISTIMEWA YOGYAKARTA
}

\author{
Bayu Aji Saputra ${ }^{1}$ dan Eka Novita Indra ${ }^{1}$ \\ ${ }^{\mathbf{1}}$ Fakultas Ilmu Keolahragaan, Universitas Negeri Yogyakarta, Colombo No. 1, Karangmalang Depok, Sleman, \\ Yogyakarta, Indonesia \\ bayu.aji@student.uny.ac.id, eka_novitaindra@uny.ac.id
}

\begin{abstract}
Abstrak
Penelitian ini bertujuan mengetahui profil fisik atlet sepatu roda di Daerah Istimewa Yogyakarta. Profil fisik yang diukur meliputi daya tahan, kekuatan otot perut, kekuatan otot lengan, kelincahan, daya ledak, kelentukan, kecepatan dan keseimbangan. Penelitian ini merupakan penelitian deskriptif kuantitatif. Metode yang dipergunakan dalam penelitian ini adalah metode survey dengan teknik pengumpulan data berupa tes dan pengukuran. Populasi dalam penelitian adalah atlet Puslatda Pra Pon Daerah Istimewa Yogyakarta yang berjumlah 12. Indikator tes dan pengukuran yaitu tes kecepatan (sprint $30 \mathrm{~m}$ ), kekuatan (sit up test dan push up test), power (standing long jump test), kelentukan (sit and reach test), kelincahan (shuttle run test), keseimbangan (stork stand), dan daya tahan (multistage fitness test). Pemilihan subjek penelitian menggunakan purposive sampling, diperoleh seluruh populasi sebagai subjek. Teknik analisis data menggunakan deskriptif. Hasil penelitian profil kondisi fisik dengan tes dan pengukuran menunjukkan hasil sebagai berikut: (1) Kecepatan atlet sepatu roda dikategorikan "kurang sekali" dengan presentase sebanyak 75\%, (2) kekuatan otot perut atlet sepatu roda dikategorikan "baik" dengan presentase sebanyak $66 \%$, (3) kekuatan otot lengan atlet sepatu roda dikategorikan "cukup" dengan presentase sebanyak 58.3\%, (4) power atau daya ledak atlet sepatu roda dikategorikan "cukup" dengan presentase sebanyak 66.6\%, (5) fleksibilitas atau kelentukan atlet sepatu roda dikategorikan "baik sekali" sekali dengan presentase sebanyak 41.6\%. (6) kelincahan atlet sepatu roda dikategorikan "baik" dengan presentase terbesar sebanyak 50\%. (7) keseimbangan dikategorikan "baik sekali" dengan presentase sebanyak 100\%. (8) daya tahan atlet sepatu roda dikategorikan "baik" dengan presentase sebanyak 50\%. Jadi penelitian ini dapat disimpulkan bahwa profil konfisi fisik atlet sepatu roda dalam kategori cukup.
\end{abstract}

Kata kunci: profil fisik, sepatu roda, Daerah Istimewa Yogyakarta

\section{PHYSICAL CONDITION PROFILE OF ROLLER SKATES ATHLETES IN THE SPECIAL REGION OF YOGYAKARTA}

\begin{abstract}
This study aims to determine the physical profile of roller skates athletes in the Special Region of Yogyakarta. The physical profile measured includes endurance, abdominal muscle strength, arm muscle strength, agility, explosive power, flexibility, speed and balance. This research is quantitative descriptive. This study use survey method with data collection techniques in the form of tests and measurements. The population in this research is all athletes of the Pre-National Sport Week of Yogyakarta Special Region which is twelve athletes join progressively in training. Test and measurement indicators namely speed test (sprint $30 \mathrm{~m}$ ), strength (sit-up test and push-up test), power (standing long jump test), flexibility (sit and reach test), agility (shuttle run test), balance (stork stand), and endurance (multistage fitness test). The selection of research subjects using purposive sampling, then obtained entire population as subjects. The data analysis technique uses descriptive. The results of the physical condition profile research with tests
\end{abstract}




\section{MEDIKORA, Vol. XVIII No. 2 Oktober 2019 - 71}

Bayu Aji Saputra, Eka Novita Indra

and measurements showed the following results: (1) The speed of roller skates was categorized as "very poor" with a percentage of 75\%, (2) the abdominal strength of roller skates was categorized as "good" with a percentage of $66 \%$, (3) the arm muscle strength of roller skates is categorized as "sufficient" with a percentage of $58.3 \%$, (4) the power or explosive power of roller skates is categorized as "sufficient" with a percentage of $66.6 \%$, (5) the flexibility or flexibility of the roller skates is categorized "Very good" with a percentage of $41.6 \%$. (6) the agility of roller skaters are categorized as "good" with the largest percentage of 50\%. (7) the balance is categorized as "very good" with a percentage of 100\%. (8) endurance of roller skaters are categorized as "good" with a percentage of 50\%. So this study can be concluded that the profile of physical roller skates athletes in the category is sufficient.

Keywords: Physical, profile, roller skate, Daerah Istimewa Yogyakarta

\section{PENDAHULUAN}

Olahraga sepatu roda sudah berkembang menjadi olahraga yang digemari lapisan masyarakat. Salah satu olahraga yang pupoler di dunia yaitu inline skating atau selancar roda sebaris atau yang lebih dikenal di masyarakat sebagai permainan sepatu roda. Adapun nomornomor yang dipertandingkan cabang olahraga sepatu roda meliputi jarak pendek $100 \mathrm{~m}, 200 \mathrm{~m}$, 300m, 500m, 1000m. Adapun nomor-nomor sepatu roda jarak jauh yaitu 5000m, 10000m, $15000 \mathrm{~m}, 21 \mathrm{~km}$ half marathon dan $42 \mathrm{~km}$ full marathon.

Membentuk atlet dengan prestasi yang maksimal tidaklah mudah, membutuhkan rangkaian proses pencarian bakat, pembinaan prestasi yang panjang maka akan dihasilkan atlet yang dapat mencapai penampilan puncak dengan prestasi yang baik. Peningkatan kondisi fisik harus lebih fokus ditingkatkan agar diperoleh kemampuan maksimal saat bertanding dalam cabang olahraga sepatu roda. Tentu saja harus memiliki kemampuan profil fisik yang mumpuni agar dapat mencapai prestasi tertinggi, sedangkan memelihara dan meningkatkan fisik membutuhkan latihan yang terukur, kontinu dan terprogram. Untuk menunjang kemampuan fisik di perluhkan komponen dasar kondisi fisik menurut Sajoto (1988: 57) meliputi kekuatan, daya tahan, kekuatan otot, kecepatan, kelentukan, kelincahan, koordinasi, keseimbangan, ketepatan dan reaksi. Karena hampir semua aktivitas gerak dalam olahraga selalu mengandung unsun-unsur kekuatan, durasi, kecepatan, dan gerak kompleks yang memerlukan keluasan gerak persendian (Bompa,1994).

Atlet yang memiliki kondisi fisik yang baik serta mempunyai biomotorik tentu akan lebih berpeluang untuk berprestasi. Untuk mengetahui seorang atlet memiliki kondisi fisik yang baik atau tidak maka perlu dilakukan tes fisik, sehingga jika terdapat atlet yang memiliki tingkat kemampuan fisik yang kurang baik akan segera dilakukan langkah-langkah perbaikan tingkat kemampuan fisik menuju tingkat yang lebih baik. Dengan mengetahui tingkat kemampuan fisik seorang atlet sepatu roda, maka dapat diprediksi kemampuan atlet dalam berprestasi di masa mendatang. Penelitian ini untuk mengetahui komponen kondisi fisik penting pada atlet sepatu roda.

\section{Hakikat Sepatu Roda}

Pada dasarnya ada tiga jenis sepatu roda skate quad, inline skate, dan tri-sepatu. Ada beberapa variasi lain seperti sepatu roda yang tunggal roda. Roller skating mencakup banyak jenis pertunjukan seperti tari solo, tari tim, dan tari gaya bebas. Menurut Powel (2009:3) sepatu roda adalah olahraga bilah gelinding (roller blading), dan sepatu luncur (the skate) sebagai bilang gelinding (roller blade). Skates inline adalah jenis sepatu roda yang digunakan untuk inline skating. Tidak seperti sepatu quad, yang memiliki dua depan dan dua roda belakang, inline skate biasanya memiliki 3-4 roda diatur alam satu baris. Beberapa terutama yang untuk rekreasi, 


\section{MEDIKORA, Vol. XVIII No. 2 Oktober 2019 - 72}

Bayu Aji Saputra, Eka Novita Indra

memiliki karet "berhenti" atau "rem" blok melekat pada bagian belakang dari satu atau kadangkadang kedua sepatu sehingga skater dapat memperlambat atau berhenti bersandar pada kaki dengan skate rem.

\section{Teknik Dasar Sepatu Roda}

Ditinjau dari pelaksanaan permainan sepatu roda bahwa, gerakangerakan yang terjadi dalam permainan adalah gerakan-gerakan dari badan dan macam-macam cara memainkan sepatu roda. Gerakan badan dan cara memainkan berdiri di atas separu roda adalah dua komponen yang saling berkaitan dalam pelaksanaan permainan sepatu roda. Gerakan-gerakan maupun cara memainkan sepatu roda tersebut terangkum dalam teknik dasar. Menurut Powel (1996 : 35-58) teknik dasar bermain sepatu roda adalah sebagai berikut: 1) Sikap tubuh. Cara berdiri (stance) penempatan sepatu roda pada permukaan yang datar, diukur lebar dan panjang. Lebar (width) adalah jarak dari kedua kaki selebar bahu dan panjang (length) adalah pemisah dari depan ke belekang. Sikap tubuh ialah posisi paha harus di tekuk 90 derajat dan posisi lutut harus sejajar dengan ujung jari-jari kaki. Dengan menekuk pergelangan kaki dan lutut ke depan meletakan berat badan di posisi telapak kaki bagian depan; 2) Mengayuh dan meluncur. Kayuhan (stroke) adalah dorongan satu kaki ke samping (side) mendorong tubuh kita ke depan dengan posisi 45 derajat. Ketika memulai kayuhan pindahkan berat badan (body move) ke badan yang tidak mengayuh menimbulkan gerakan meluncur; 3) Ayunan lengan. Ayunan lengan (arm swing) adalah ayunan lengan yang lurus ke depan dan belakang. Ayunan lengan tidak boleh lebih tinggi atau rendah dari bahu saat mengayun harus posisi telapak tangan menghadap ke badan serta rileks; 4) Cara berhenti. Cara berhenti (stopping) adalah posisi kaki kanan di depan lalu angkat telapak kaki bagian depan sampai bantalan rem menyentuh dasar. Ada cara lain untuk bisa berhenti dengan teknik stopan T (brake stop) dilakukan dengan menarik sepatu roda yang di belakang pada sudut 90 derejat dari arah gerakan. Pengereman terjadi karena posisi sepatu roda pada pinggir sebelah dalam roda dapat; 5) Cara berbelok. Cara berbelok adalah satu kaki sepatu roda berada di depan sebelah sepatu yang lain akan membantu untuk berbelok. Untuk berbelok kanan sepatu roda yang sebelah kanan harus berada di depan sebelah kiri akan mengikuti dan untuk berbelok kiri sepatu roda sebelah kiri berada di depan.

\section{Hakikat Kondisi Fisik}

Kondisi fisik merupakan unsur penting dan dasar untuk pengembangan teknik, taktik maupun strategi. Fisik merupakan pondasi prestasi olahragawan, sebab teknik, taktik dan mental akan dapat dikembang dengan baik jika memiliki kualitas fisik yang baik (Irianto, 2002: 65). Menurut Sajoto (1988: 57) kondisi fisik adalah salah satu prasyarat yang di perluhkan dalam setiap usaha peningkatan prestasi seorang diri, bahkan dapat dikatakan sebagai dasar landasan titik tolak suatu awal olahraga prestasi. Artinya bahwa di dalam usaha peningkatan kondisi fisik maka seluruh komponen tersebut harus berkembang. Tujuan utama persiapan fisik menurut Bompa (1994: 50) dalam Nugroho (2011: 50) adalah untuk meningkatkan potensi fungsional atlet dan mengembangkan kemampuan biomotor kestandar yang paling tinggi.

\section{Komponen Kondisi Fisik}

Komponen kondisi fisik tidak bisa dipisahkan dalam meningkatkan ataupun memelihara kondisi. Sedangkan menurut Sajoto (1988: 57) adalah satu kesatuan utuh dari komponen komponen yang tidak bisa dipisahkan, baik peningkatan, maupun pemeliharaanya. Mengandung arti bahwa setiap usaha peningkatan kondisi fisik, maka harus mengembangkan semua komponen 


\section{MEDIKORA, Vol. XVIII No. 2 Oktober 2019 - 73}

Bayu Aji Saputra, Eka Novita Indra

tersebut. Menurut Sajoto (1988: 57) komponen-komponen kondisi fisik sebagai berikut: 1) Kekuatan (strength) adalah komponen kondisi fisik seseorang tentang kemampuannya dalam mempergunakan otot untuk menerima beban sewaktu bekerja; 2) Daya tahan (endurance) ada 2 dua macam, yaitu: a) Daya tahan umum yaitu kemampuan seseorang dalam mempergunakan sistem jantung, paru-paru dan peredaran darahnya secara efektif dan efisien. b) Daya tahan otot adalah kemampuan seseorang dalam mempergunakan ototnya untuk berkontraksi secara terus menerus dalam waktu yang relatif lama dengan beban tertentu; 3) Kekuatan otot (muscular power) adalah kemampuan seseorang dalam mempergunakan kekuatan maksimum yang digunakan dalam waktu yang sesingkat singkatnya; 4) Kecepatan (speed) adalah kemampuan seseorang untuk mngerjakan gerakan keseimbangan dalam bentuk yang sama dalam waktu yang sesingkat singkatnya; 5) Kelentukaan (flexibility) adalah efektivitas seseorang dalam penyelesaian diri untuk segala aktivitas dengan penguuran tubuh yang luas; 6) Kelincahan (agility) adalah kemampuan mengubah posisi diarea tertentu; 7) Koordinasi (coordination) adalah kemampuan seseorang melakukan bermacam-macam gerakan yang berbeda ke dalam pola gerakan tunggal secara efektif; 8) Keseimbangan (balance) adalah kemampuan tubuh untuk mempertahankan posisi, dalam bermacam-macam gerakan; 9) Ketepatan (accuracy) adalah kemampuan seseorang untuk mengendalikan gerakan bebas terhadap sasaran; 10) Reaksi (reaction) adalah kemampuan seseorang untuk segera bertindak secepatnya dalam menggapai rangsangan yang ditimbulkan melalui indera, saraf atau feeling lainya. Seperti dalam mengantisipasi datangnya bola yang harus ditangkap dan lain-lain.

Pemeliharaan dan peningkatan berbagai komponen tidak dapat terlepas antara satu dengan yang lain, sehingga prestasi seorang atlet dalam berbagai cabang olahraga dapat meningkat jika keseluruhan item penunjang kondisi fisik diperoleh dengan nilai yang memuaskan.

\section{METODE}

Penelitian ini merupakan penelitian deskriptif kuantitatif yang salah satu cirinya adalah tidak ada hipotesis dan data yang terkumpul dipresentasikan. Penelitian deskriptif tidak dimaksudkan untuk menguji hipotesis tertentu, tetapi menggambarkan apa adanya tentang variabel, gejala atau suatu keadaan. Metode yang digunakan dalam penelitian metode survey dengan menggunakan teknik pengumpulan data berupa tes dan pengukuran.

\section{Subjek Penelitian}

Populasi dalam penelitian ini adalah atlet sepatu roda DIY sebanyak 12 atlet. Subjek dalam penelitian ini seluruh populasi. Karatristik populasi dengan pertimbangan tertentu Seluruh populasil tersebut dikenai pretest selanjutnya kelompok (1) atlet sepatu roda Pra Pon puslatda DIY, (2) atlet usia 13-20 tahun, (3) pernah atau sedang mempersiapkan diri mengikuti ajang kompetisi baik tingkat kabupaten/kota, provinsi, maupun nasional. Berdasarkan pertimbangan tersebut, subjek yang digunakan dalam penelitian ini adalah atlet sepatu roda pra pon DIY sejumlah 12 atlet.

\section{Teknik Pengumpulan Data}

Dalam penelitian ini metode yang dilakukan adalah menggunakan metode survei dengan teknik pengumpulan data yaitu tes dan pengukuran yang dilakukan oleh pengukur terhadap subjek. Variabel dalam penelitian ini adalah profil kondisi fisik atlet sepatu roda DIY tahun 2018. Difinisi variabel komponen kondisi fisik atlet yang di ukur berdasarkan indikator: kecepatan, kekuatan, kelincahan, kelentukan, keseimbangan, daya tahan, daya ledak, menggunakan tes pengukuran (1) 
test sprint $30 \mathrm{~m}$ (2) sit-up, (3) push-up, (4) standing long jump test, (5) sit and reach test, (6) shuttle run test, (7) multistage fitness test (8) stork stand.

\section{HASIL DAN PEMBAHASAN}

Berdasarkan hasil penelitian tentang profil fisik atlet sepatu roda di Daerah Istimewa Yogyakarta menggunakan tes dan pengukuran, telah di dapat kan hasil setiap komponen tes dan dapat di jelaskan sebagai berikut:

Kemampuan tes untuk kecepatan menggunakan Tes Sprint $30 \mathrm{~m}$, dari hasil tes kecepatan atlet sepatu roda putra dan putri sebagian besar masuk dalam kategori kurang sekali sebanyak 9 atlet atau $75 \%$ dari total frekuensi. Profil fisik untuk kecepatan masih perlu ditingkatkan lagi dengan melatih komponen kecepatan agar dapat masuk dalam kategori "baik", tetapi harus didahului latihan ketahanan dan kekuatan.

Tabel 1. Tes kecepatan menggunakan Tes Sprint $30 \mathrm{~m}$.

\begin{tabular}{|c|c|l|c|c|}
\hline \multicolumn{2}{|c|}{ Interval Kategori } & \multicolumn{2}{c|}{ Putri } \\
\cline { 5 - 6 } Putra & Putri & & F & $\%$ \\
\hline$<4.0$ & $<4.5$ & Baik sekali & 0 & 0 \\
\hline $4.2-4.0$ & $4.6-4.5$ & Baik & 0 & 0 \\
\hline 4.44 .3 & $4.8-4.7$ & Cukup & 0 & 0 \\
\hline $4.6-4.5$ & $5.0-4.9$ & Kurang & 3 & 25 \\
\hline$>4.6$ & $>5.0$ & Kurang sekali & 9 & 75 \\
\hline Jumlah & & $\mathbf{1 2}$ & $\mathbf{1 0 0}$ \\
\hline
\end{tabular}

Kemampuan tes kekuatan otot perut menggunakan Tes Sit Up. Berdasar kan hasil tes didapatkan hasil bahwa sebagian besar atlet sepatu roda putra dan putri masuk dalam kategori "baik" yaitu sebanyak 8 atlet atau sebesar $66 \%$ dari total frekuensi.

Tabel 2. Tes kekuatan otot perut menggunakan tes Sit Up.

\begin{tabular}{|c|c|l|c|c|}
\hline \multicolumn{2}{|c|}{ Interval } & \multirow{2}{*}{ Kategori } & \multicolumn{2}{c|}{ Putra } \\
\cline { 5 - 6 } Putra & Putri & & F & \% \\
\hline $70>$ & $70>$ & Baik sekali & 3 & 25 \\
\hline $54-49$ & $54-49$ & Baik & 8 & 66 \\
\hline $38-53$ & $38-53$ & Cukup & 1 & 8.3 \\
\hline $22-37$ & $22-37$ & Kurang & 0 & 0 \\
\hline$<21$ & $<21$ & Kurang sekali & 0 & 0 \\
\hline Jumlah & & $\mathbf{1 2}$ & $\mathbf{1 0 0}$ \\
\hline
\end{tabular}

Kemampuan tes kekuatan otot lengan dan bahu menggunakan Tes Push Up. Berdasarkan hasil tes kekuatan otot lengan atlet sepatu roda putra dan putri sebagian besar masuk dalam kategori "cukup" yaitu sebanyak tujuh atlet atau sebesar 58.3\% dari total frekuensi. 
MEDIKORA, Vol. XVIII No. 2 Oktober 2019 - 75

Bayu Aji Saputra, Eka Novita Indra

Tabel 3. Tes kekuatan otot lengan dan bahu menggunakan tes Push Up.

\begin{tabular}{|c|c|l|c|c|}
\hline \multicolumn{2}{|c|}{ Interval Kategori } & \multicolumn{2}{c|}{ Putra } \\
\cline { 5 - 6 } Putra & putri & & F & \% \\
\hline $70>$ & 70 & Baik sekali & 0 & 0 \\
\hline $53-69$ & $52-69$ & Baik & 0 & 0 \\
\hline $38-52$ & $34-51$ & Cukup & 7 & 58.3 \\
\hline $19-35$ & $16-33$ & Kurang & 5 & 41.6 \\
\hline$<18$ & $<$ & Kurang sekali & 0 & 0 \\
\hline \multicolumn{2}{|l}{} & $\mathbf{1 2}$ & $\mathbf{1 0 0}$ \\
\hline
\end{tabular}

Kemampuan tes power/daya ledak otot tungkai menggunakan Tes Standing Long Jump. Berdasarkan hasil tes power/daya ledak otot tungkai atlet sepatu roda putra dan putri sebagian besar berada pada kategori "cukup" yaitu sebanyak delapan atlet atau sebesar $66 \%$ dari total frekuensi.

Tabel 4. Tes power/daya ledak otot tungkai menggunakan tes Standing Long Jump.

\begin{tabular}{|c|c|l|c|c|}
\hline \multicolumn{2}{|c|}{ Interval } & \multicolumn{2}{c|}{ Kategori } & \multicolumn{2}{c|}{ Putri } \\
\cline { 4 - 6 } Putra & Putri & & F & \% \\
\hline $3.15-2.80$ & $2.97-2.55$ & Baik sekali & 0 & 0 \\
\hline $2.79-2.54$ & $2.54-2.25$ & Baik & 0 & 0 \\
\hline $2.53-2.20$ & $2.24-2.00$ & Cukup & 8 & 66.6 \\
\hline $2.19-1.90$ & $1.99-1.60$ & Kurang & 4 & 33.3 \\
\hline $1.89>$ & $1.59>$ & Kurang sekali & 0 & 0 \\
\hline Jumlah & & $\mathbf{1 2}$ & $\mathbf{1 0 0}$ \\
\hline
\end{tabular}

Kemampuan tes fleksibilitas / kelentukan menggunakan Tes Sit and Reach. Berdasarkan hasil tes fleksibilitas / kelentukan atlet sepatu roda putra dan putri sebagian besar masuk dalam kategori baik "baik sekali" yaitu sebanyak 5 atlet atau $41 \%$ dari total frekuensi. Dari hasil tes yang didapatkan kelentukan atlet sepatu roda pada umumnya masih sekitar $41 \%$ kategori "baik sekali" diharapkan pelatih mampu meningkatkan beberapa atlet yang lainnya juga.

Tabel 5. Tes fleksibilitas / kelentukan menggunakan tes Sit and Reach.

\begin{tabular}{|c|c|l|c|c|}
\hline \multicolumn{2}{|c|}{ Interval Kategori } & \multicolumn{2}{c|}{ Putri } \\
\cline { 5 - 6 } Putra & Putri & & F & \% \\
\hline 19,5 & $20,0-23,0$ & Baik sekali & 5 & 41.6 \\
\hline $17,0-19,0$ & $18,5-19,5$ & Baik & 3 & 25 \\
\hline $14,5-16,5$ & $17,0-18,0$ & Cukup & 3 & 25 \\
\hline $12,5-14,0$ & $15,0-16,5$ & Kurang & 0 & 0 \\
\hline$<12,0$ & $13,5-14,5$ & Kurang sekali & 0 & 0 \\
\hline Jumlah & & $\mathbf{1 2}$ & $\mathbf{1 0 0}$ \\
\hline
\end{tabular}

Kemampuan tes kelincahan menggunakan Tes Shuttle Run. Berdasarkan hasil tes kelincahan atlet sepatu roda putra dan putri sebagian besar masuk dalam kategori "baik" sebanyak 6 anak atau $50 \%$ dari total frekuensi. 
MEDIKORA, Vol. XVIII No. 2 Oktober 2019 - 76

Bayu Aji Saputra, Eka Novita Indra

Tabel 6. Tes kelincahan menggunakan Tes Shuttle Run.

\begin{tabular}{|c|c|l|c|c|}
\hline \multicolumn{2}{|c|}{ Interval } & \multicolumn{2}{c|}{ Kategori } & \multicolumn{2}{c|}{ Putri } \\
\cline { 5 - 6 } Putra & Putri & & F & $\mathbf{\%}$ \\
\hline$<12.10$ & $<12.42$ & Baik sekali & 0 & 0 \\
\hline $12.11-13.53$ & $12.43-14.09$ & Baik & 6 & 50 \\
\hline $13.54-14.96$ & $14.10-15.74$ & Cukup & 5 & 41.6 \\
\hline $14.98-16.39$ & $15.75-17.39$ & Kurang & 1 & 8.3 \\
\hline $16.40>$ & $17.40>$ & Kurang sekali & 0 & 0 \\
\hline Jumlah & & $\mathbf{1 2}$ & $\mathbf{1 0 0}$ \\
\hline
\end{tabular}

Kemampuan tes keseimbangan menggunakan Tes Stork Stand. Berdasarkan hasil tes keseimbangan atlet sepatu roda putra dan putri sebagian besar masuk dalam kategori "baik sekali" sebanyak 12 atlet atau 100\% dari total frekuensi.

Tabel 7. Tes keseimbangan menggunakan tes Stork Stand.

\begin{tabular}{|c|c|l|c|c|}
\hline \multicolumn{2}{|c|}{ Interval } & \multicolumn{2}{c|}{ Kategori } & \multicolumn{2}{c|}{ Putra } \\
\cline { 5 - 6 } Putra & Putri & & F & $\%$ \\
\hline$>50$ & $>30$ & Baik sekali & 12 & 100 \\
\hline $41-50$ & $23-30$ & Baik & 0 & 0 \\
\hline $31-40$ & $16-22$ & Cukup & 0 & 0 \\
\hline $20-30$ & $10-15$ & Kurang & 0 & 0 \\
\hline$<20$ & $<10$ & Kurang sekali & 0 & 0 \\
\hline Jumlah & & $\mathbf{1 2}$ & $\mathbf{1 0 0}$ \\
\hline
\end{tabular}

Kemampuan tes daya tahan/ketahanan menggunakan Tes Multistage Fitness. Berdasarkan hasil tes daya tahan/ketahanan atlet sepatu roda putra dan putri sebagian besar masuk dalam kategori "cukup" sebanyak 6 atlet atau 50\% dari total frekuensi.

Tabel 8. Tes daya tahan/ketahanan menggunakan Tes Multistage Fitness.

\begin{tabular}{|c|c|l|c|c|}
\hline \multicolumn{2}{|c|}{ Interval } & \multirow{2}{*}{ Kategori } & \multicolumn{2}{c|}{ Putra } \\
\cline { 5 - 5 } Putra & Putri & & F & \% \\
\hline$<51.6$ & $<51.6$ & Baik sekali & 1 & 8.3 \\
\hline $42.6-51.5$ & $42.6-51.5$ & Baik & 4 & 33.3 \\
\hline $33.8-42.5$ & $33.8-42.5$ & Cukup & 6 & 50 \\
\hline $25.0-33.7$ & $25.0-33.7$ & Kurang & 0 & 0 \\
\hline$>25.0$ & $>25.0$ & Kurang sekali & 0 & 0 \\
\hline Jumlah & & $\mathbf{1 2}$ & $\mathbf{1 0 0}$ \\
\hline
\end{tabular}

Komponen biomotor yang dijadikan sebagai instrument penelitian ini mencapai 8 bentuk. Keseluruhan aspek yang di-tes-kan memberikan andil yang besar terhadap kesuksesan atlet sepatu roda dalam kompetisi.

Pada olahraga sepatu roda, kecepatan memiliki peran penting pada saat terjadi saling adu kecepatan kemampuan untuk nomer jarak pendek. Tes kecepatan atlet sepatu roda putra dan putri pada penelitian ini, sebagian besar masuk dalam kategori kurang sekali sebanyak 9 atlet atau 75\% dari total frekuensi. Mengindikasikan adanya kekurangan dalam hal kecepatan padahal pengaruhnya begitu besar terhadap performa atlet. Sebagai komponen dasar biomotor (Bompa, 


\section{MEDIKORA, Vol. XVIII No. 2 Oktober 2019 - 77}

Bayu Aji Saputra, Eka Novita Indra

1994), seharusnya pelatih harus dapat meningkatkan kualitas kecepatan gerak dan reaksinya, karena akan sangat berpengaruh pada performa saat latihan ataupun saat bertanding. Pelatih juga harus memperhatikan komponen kecepatan ini agar dapat mendukung perkembangan prestasi atlet sehingga para atlet diharapkan akan mencapai puncak prestasi.

Kemampuan kekuatan otot perut atlet sepatu roda putra maupun putri harus di tingkatkan lagi, meskipun sebagian besar atlet sepatu roda putra dan putri masuk dalam kategori "baik" yaitu sebanyak 8 atlet atau sebesar 66\% dari total frekuensi. Usaha peningkatan yang dilakukan bertujuan agar dapat masuk dalam kategori "baik sekali", dikarenakan kemampuan otot perut merupakan kemampuan inti (core) yang harus dimiliki oleh setiap atlet, tidak hanya pada sepatu roda saja. Kekuatan otot perut berfungsi pada saat start di semua nomer pertandingan (Powel, 1996).

Kekuatan otot lengan atlet sepatu roda putra dan putri sebagian besar masuk dalam kategori "cukup" yaitu sebanyak tujuh atlet atau sebesar 58.3\% dari total frekuensi. Kekuatan otot lengan dan bahu untuk atlet sepatu roda berfungsi pada saat mengayun untuk menambah kecepatan. Begitu juga pada nomer beregu yang mengharuskan atlet untuk mendukung seluruh kemampuan yang dimiliki dari setiap atlet untuk bisa menambah atau menstabilkan kecepatan. Seorang atlet yang tidak memiliki kekuatan otot lengan dan bahu yang baik akan mengalami kesulitan untuk bermain beregu maupun nomer individu.

Fleksibilitas atlet sepatu roda mempunyai kelentukan yang baik maka akan membantu pemulihan di saat program latihan dengan intensitas tinggi mengurangi resiko cedera (Bompa, 1994). Fleksibilitas / kelentukan atlet sepatu roda putra dan putri pada penelitian ini, sebagian besar masuk dalam kategori "baik sekali" yaitu sebanyak 5 atlet atau $41 \%$ dari total frekuensi. Mengindikasikan bahwa mayoritas masih dalam kategori cukup, manfaat kelenturan sangat dapat dirasakan oleh pada atlet sepatu roda ketika melakukan akselerasi tinggi pada saat belokan, dimana atlet harus mempertahankan kecepatan dengan posisi merunduk. Posisi menundukkan kepala akan membuat orang dengan kelenturan rendah cepat merasakan capek atau pegal atau kelelahan. Peningkatan komponen fleksibilitas dibutuhkan untuk menyokong kemampuan atlet dalam bergerak selama aktivitas berlangsung.

Setengah dari atlet sepatu roda putra dan putri masuk dalam kategori "baik" sebanyak 6 anak. Kelincahan menjadi salah satu faktor penting untuk olahraga sepatu roda untuk dapat mengambil posisi saat pengambilan point di nomer pertandingan point race maupun untuk mendapatkan kemenangan. Sementara itu, komponen keseimbangan menjadi salah satu kebutuhan dasar yang harus dimiliki oleh atlet sepatu roda. Dari hasil penelitian ini, atlet sepatu roda putra dan putri sebagian besar masuk dalam kategori "baik sekali" sebanyak 12 atlet atau 100\%. Baiknya angka keseimbangan akan berdampak pada performa ketika latihan atau bertanding. Komponen keseimbangan dominan pada semua bentuk gerak pada cabang olahraga sepatu roda (Powel, 1996).

Terakhir, dalam komponen kapasitas aerobik, Jika seorang atlet memiliki kemampuan menghirup oksigen dalam jumlah yang tinggi maka akan cepat melakukan recovery dengan cepat sehingga mampu melakukan latihan dengan intensitas tinggi. Namun, tes daya tahan/ketahanan atlet sepatu roda putra dan putri sebagian besar masuk dalam kategori "cukup" sebanyak 6 atlet atau 50\% dari total frekuensi. Peningkatan kemampuan kardiovaskular dapat dilakukan dalam 24 kali pertemuan atau selama 3 bulan latihan intensif dengan peningkatan bisa mencapai rata-rata 3 poin (Bompa, 1994). Hal ini sangat diperlukan mengingat kondisi $\mathrm{VO}_{2} \mathrm{Max}$ atlet putra putri pada penelitian ini hanya memiliki kondisi kapasitas aerobik dalam kategori cukup 
Kondisi fisik yang baik mempunyai beberapa keuntungan, di antaranya atlet mampu dan mudah mempelajari keterampilan yang relatif sulit, tidak mudah lelah ketika mengikuti latihan atau pertandingan, program latihan dapat diselesaikan tanpa adanya banyak kendala serta dapat dapat menyelesaikan latihan yang berat. Kondisi fisik sangat diperlukan oleh seorang atlet, karena tanpa didukung oleh kondisi fisik yang prima maka pencapaian prestasi puncak akan mengalami banyak kendala dan mustahil dapat meraih prestasi tinggi. Dengan adanya penelitian ini, diharapkan pelatih dan atlet dapat mengetahui status kondisi fisiknya, sehingga bagi pelatih dan atlet untuk lebih menjaga dan mempertahankan kondisi fisiknya menjadi lebih baik.

Diharapkan pelatih dapat memberikan latihan yang dapat meningkatkan power/daya ledak otot tungkai pada atlet speatu roda karena hal tersebut sangat masih bisa ditingkatkan dan dikembangkan lagi untuk menuju puncak prestasi. Meskipun demikian pelatih harus memberikan latihan kekuatan dan kecepatan lebih dahulu sebelum memasuki latihan power, bukan hanya berdasarkan pengalaman pribadi atau pun menonton tayangan youtube. Atlet yang memiliki power baik akan mempengaruhi kemantapan gerak terutama pada teknik meluncur.

\section{SIMPULAN}

Dari hasil analisis data, deskripsi, pengujian hasil penelitian dan pembahasan, dapat diambil kesimpulan bahwa profil kondisi fisik atlet sepatu roda tahun di Daerah Istimewa Yogyakarta masuk dalam kategori cukup.

\section{DAFTAR PUSTAKA}

Bompa T. O. (1994). Total Training for Young Champions (Terjemahan). USA: Human Kinetics. Irianto, D. P. (2002). Dasar Kepelatihan. Yogyakarta: Diktat.

Harsono. (2017). Kepelatihan Olahraga. Bandung: Remaja Rosdakarya Offset. Komarudin. (2016). Psikologi Olahraga. Bandung : Remaja Rosdakarya Offset.

Nugroho, A. (2011). Standarisasi Status Kondisi Fisik Atlet Cabor Perorangan Koni Daerah Istimewa Yogyakarta. Fakultas Ilmu Keolahragaan. No 49-63.

Powel, M. dan Svensson, J. (1996). In-Line Skating (Terjemahan). Jakarta: Rajagrafindo Persada. Sajoto, M. (1988). Pembinaan Kondisi Fisik Dalam Olahraga. Jakarta: Dirjen Dikti P2LPTK. Depdikbud. 